\title{
The Impact of Micro and Small Enterprises in the Socio-Economic Development and the Challenges Encountering the Sector in Ethiopia: A Systematic Review
}

\author{
Desalegn Fekadu Etefa, PhD Candidate
}

\begin{abstract}
Micro and Small Enterprises (MSEs) are one of the means of poverty alleviation strategies particularly in developing countries like Ethiopia. They are the backbone for advancement and also lay bases for the economic transformation. Being cognizant of their role as essential vehicles in accelerating socio-economic development, the current government of Ethiopia issued National MSEs Strategy in 1997 and established MSEs Development Agency in 1998. As a result, abundant numbers of MSEs and employment opportunities are created in Ethiopia, which have shown increasing trend overtime. The intention of this review was to examine the status and the main challenges impeding the performances of the MSEs in Ethiopia. To do so, an appropriate methodology employed was descriptive research design. The type of methodological approach was best evidence review. The source of data used is secondary from the literature review and articles of different materials. The instruments used for data collection is review of compiled documents. The study shows that in spite of their growing contributions, MSEs in Ethiopia are encountered with various challenges among which, financial, managerial, technological and technical skills, business development services, infrastructure, policy related and institutional linkage are the most important identified challenges hindering the progresses of the sector. Thus, to enable the MSEs fully contribute the rationale of their establishment, collective efforts are required from all the stakeholders including the entrepreneurs themselves to confront the specified obstacles.
\end{abstract}

Keywords: Micro and Small Enterprises; Employment Creation; Capital Formation; Livelihood Improvement; Socio-Economic Development; Challenges; Interventions

DOI: $10.7176 / \mathrm{EJBM} / 11-25-05$

Publication date:September $30^{\text {th }} 2019$

\section{Introduction}

The contribution of micro and small enterprises (MSEs) in economic development, during the era of the firstgeneration, had repetitively been marginalized and even taken the wrong way. As to their perception by then, MSEs were believed to retard economic growth (Audretsch, et al. cited in Hailai et al., 2019).

However, with the advancement of science and technology, the new way of thinking appeared which altered the knowledge and attitude of people towards MSEs. In the time when many people sense incapable to change their lives because of poverty that abolished the lives of billions of the people around the world, seeking solution was the main agenda of the new generation. In this hardship situation when alleviation of poverty has become the biggest challenge to the human society, MSEs emanated to be one of the greatest economic opportunities (Desalegn, 2019). Thus, the changing patterns in the life of societies resulted in small business to be the key element and deriving force in generating employment and realizing economic development. This paradigm shift has, in turn, brought a revival in the promotion of small businesses and entrepreneurial initiative at local, national and international levels.

It is obvious that any nations could not achieve a viable economic growth and development without having functional economic base. Thus, there is consensus among developed and developing countries that small enterprises form the foundation for the economic growth of every nation. As a result, the quest of any nation's development must be centered around MSEs; because of its great role in terms of production activities, employment generation and the overall improvement in the qualities of the life of people (Mohammed, 2016). Due to this fact, policy makers and donors have progressively appreciated the roles of MSEs in creating employment and income generation with the dual objective of enhancing economic growth and sustainable development (Beck \& Levine in Mesfin, 2015).

Likewise, the research finding of Anamekwe (2001) indicated that the small business sector is recognized as an integral component of economic development and essential element specifically in the developing countries to lift people out of poverty. They are the means through which quicker economic growth and rapid industrialization will be achieved.

The small-scale industries play an important role in assisting bigger industries and projects so that the planned activity of development work is timely accomplished. They support the growth of large industries by providing, components, accessories and semi-finished goods required by them. In fact, small industries can exhale vitality into the life of large industries (Mohammed, 2016).

In developing countries, the economic importance of MSEs is also greater. For instance, in Sub-Saharan 
African countries, the sector is important in urban economic activities, particularly in the provision of urban employment and income generation (Harding \& Liedholm, 2002).

The role of MSEs in developing countries like Ethiopia is very pivotal towards employment generation, rural development, creating regional balance in promotion and growth of various development activities. MSEs play fundamental role for poor societal groups especially for women, as a poverty mitigation strategy and typically for employment creation (Rahel \& Issac, 2010).

In the same way, MSEs are seen as an emerging private sector, making the basis for private-sector-led growth (Gebrehiwot \& Wolday, 2006). Owing to these facts, the current government of Ethiopia issued National Micro and Small Enterprises Strategy in 1997 and established Micro and Small Enterprises Development Agency in 1998 at federal level (Tariku, 2018a).

In addition, the government gave distinct consideration to the development of Micro and Small Enterprises (MSEs) since 2002 after realizing the contributions of the sector in the socio-economic development. To achieve this goal, the government adapted four consecutive Poverty Reduction Strategies in urban poverty reduction (Yared, 2017). According to the report of CSA (2003), MSEs account for the bulk of non-agricultural economic activities and nearly $95.6 \%$ of the total industrial employment.

Evidence indicated that the numbers of MSEs and Employment opportunities created in Ethiopia are in growing tendency overtime. For example, in 2010/11 and 2018/19, there were 51,983 and 799,358 MSEs respectively, whereas, the number of job employment created was 806,322 and 997,380 during the same period (National Bank of Ethiopia \& Tariku, 2018b). Despite this increasing trend, the MSEs sector in Ethiopia is exposed to numbers of constraints related to policy, and structural and institutional problems that hinder sustained growth, development and long term planning (Ageba \& Amha, 2003).

Moreover, Mesfin (2015) pointed out that regardless of the anticipated contributions of small enterprises to economic vitality, failure and bankruptcy has plagued these enterprises in most Sub-Saharan countries including Ethiopia (Eshetu \& Eleke, 2008). According to Timmons and Spinelli, (2004), lack of business skills, limited access to finance and unfavorable economic climate are the most serious causes of bankruptcy among small enterprises. Added to this, this programme is failed to bring about continuous growth and development of small enterprises due to the fact that small-sized enterprises are particularly vulnerable to bankruptcy, arising from problems related to business and managerial skills and access to finance and macroeconomic policy (Craig, Jackson \& Thomson 2007).

Thus, the purpose of writing this article review is to examine and describe the difficulties and prospects of entrepreneurs running small enterprises. Specifically, it identifies sector-specific growth constraints and, in doing so, aims to assist the government and other stakeholders in their efforts to promote the growth and expansion of small enterprises by employing different strategies in the various sectors. To this end, the rationale of the review is to examine the status and the major challenges impeding the performance of the MSEs in Ethiopia. What's more, the review could serve as a stepping-stone for academicians and consultants who may be focusing on similar topics and issues, particularly the challenges facing entrepreneurs and their prospects in small enterprises. It is also significant as it recommends some practical measures to overcome the constraints facing small businesses, therefore enabling them to play a key role in the reduction of absolute poverty and in the industrialization efforts made by the country at large.

\section{Reviews of Related Literature}

\subsection{Conceptual Definition of Micro and Small Enterprises}

Numerous researchers in the discipline of development agree that there is no universally accepted definition of MSEs. Different countries offer definition to MSEs reliant on their interests, which in turn depend upon the pattern and stage of development, their policy and their countries' administrative set up. Varying definitions among countries may arise from differences in industrial organization at different levels of economic development in parts of the same country (Anamekwe, 2001).

For instance, in some countries, either numbers of employees or capital investment or both have been used as the basis for defining MSEs (Tariku, 2018a). In the same way, in Ethiopia too, single definition is not given to MSEs at the national level. This shows various governments, organizations and scholars define the sector based on their own standards.

Of these, Ministry of Trade and Industry (MoTI) (1997), uses capital investment as a yardstick to define the MSEs. On the other hand, the Central Statistical Agency (CSA) uses employment and favors capital intensive technologies as a touchstone. This agency labels enterprises into different scales of operation on the size of employment and the nature of equipment. Accordingly, establishments employing less than ten persons and using motor operated equipment are considered as small scale manufacturing enterprises (CSA, 2003). Enterprises in the micro enterprise category are subdivided into informal sector operations and cottage industries. As to this classification, cottage and handicraft industries are those establishments performing their activities by hand and using non-power driven machines whereas the informal sector is categorized as household type establishments or 
activities, which are non-registered companies and cooperatives operating with less than 10 persons (Tariku, 2018a).

However, the definition provided by CSA concentrated on manufacturing ignoring other sectors and failure in using size of capital, while that of MoTI focused on capital. This signifies none of them have provided complete description. Thus, due to lack of uniform definition given to the sector, the agency failed to gather data about cottage and handicraft industries for the last 10 years. Consequently, the data collected from the MSEs lack consistency and encountered difficulty to analyze and to interpret in logical ways (Federal Micro and Small Enterprises Development Agency) (FeMSEDA, 2011).

Nonetheless, at present, as to the modified strategy of MSEs in 2011, they are categorized into micro and small enterprises depending on their human resource, sector and capital base. Accordingly, micro enterprises category include firms which have up to 5 employees (including the owner or family) and their total asset is less than or equal to Birr 100,000 for industrial sector and less than or equal to Birr 50,000 for service sector. On the other hand, small enterprises are firms which have human resources ranging from 6 to 30 and whose total asset is between Birr 100, 001 to 1,500,000 for industrial sector and between Birr 100,001 to 500,000 for service sectors (Wolday, 2015).

\subsubsection{The Procedures of MSEs Establishment in Ethiopia}

According to the 2011 strategy and directives of Ethiopia MSEs, the following procedures and criteria's; are considered as the due process of entrepreneurial set up. These are: Registration for unemployment at district level, passing the selection criteria to be considered as active unemployed, preparing project proposal (jointly with local MSE offices), trade registration and licensing from Trade and Development office, market facility (display shops or manufacturing production site), starting up $20 \%$ saving to get $80 \%$ loan at regional saving and credit institutions and finally obtaining loan based on the saved amount.

\subsubsection{Distinguishing Features of the 2006 MSEs Strategy from the 2011 MSEs Strategy}

In order to accommodate the complex nature of MSEs, the government of Ethiopia has gone through some amendment since 2011. Accordingly, there were some distinguishing features that identify the new strategy from the old one. The new definition of MSEs are based on manpower and total asset, one clustered marketing and display site, saving $20 \%$ to get $80 \%$ loan, one site production and manufacturing, Lease system to buy big machineries and vehicles with payback of 40 years, tax holiday based on MSEs typology and nature, persistent training and capacity building, formal accounting and auditing procedures, limited transformation period from 13 years, structural arrangement at district and town administration level, decreasing the minimum number of MSE to sole ownership and provide new MSE type like cooperative, share company and other. Moreover, as to the new strategy, the town administration is responsible to be as collateral only if the MSE members are more than 10 individuals (FeMSEDA, 2011 cited in Yared, 2017).

\subsection{Historical Development of MSEs at Global Level}

In countries where adequate supports were provided, micro and small enterprises have found to be effective and vibrant (Solymossy \& Penna, 2000; Muma, 2002). For instance, Japan was reliant on small enterprises for its competitiveness before World War II. After the war, however, it slowly became modernized, raising and establishing harmonizing linkages to large enterprises (Gebrehiwot, 2006). In China and Taiwan too, these sectors have played a vigorous role in the industrialization efforts of their countries (Goedhuys, 2002; Lutkenhorst, 2004; Schramm, 2004).

According to Harabi (2003) \& Audretsch (2005), Taiwan developed fast by succeeding the divergent path taken by Japan and Italy, depending on the position and flexible specialization strategies devised by its small-and medium-scale industries. The growth of small enterprises can amplify the manufacturing sector and foster competitiveness besides promoting a more equitable distribution of the benefits of economic growth. Additionally, it alleviates some of the problems associated with uneven income distribution (Beaver \& Jennings, 1997 cited in Mesfin, 2015).

In Sub-Saharan African countries, the prominence of small enterprises became very high with augmented urban population dynamics (Goedhuys, 2002). The fact that there are rapid rural-urban migrations and that urban centers are verifying insufficient in absorbing these migrants, makes the sector essential in providing employment prospects (Zewde, 2002).

\subsection{Historical Development of MSEs in Ethiopia}

As evidence exhibits, the development of micro and small enterprises were integrated in the public policy of Ethiopia during the Axumite Kingdom around the first century A.D. for the first time (Mesfin, 2015). In line to this, Gurmeet \& Rakesh (2008) claimed that when Axumite Realm began minting its own gold, silver and bronze coins the fastest growth of ancient household enterprises occurred during the second century. They were using these to purchase raw materials and professional services from these private organizations to perform various buildings. 
According to the view of Mulu (2009), in the history of the country, the first imperial policy giving attention to the small enterprises of the Ethiopian economy appeared after 1855, through the domination of the progressive leader of the period, Emperor Theodros II (1855- 1867). The emperor understood the significance of the private business sectors from his comparative understanding of Europe's considerable advancement. However, Emperor Theodros's policy was unsuccessful to bear his desires to execution (Taye, 1998; Mulatu, 2005).

Following the death of Emperor Yohannes IV (1870 to 1887), Emperor Minilk came to power (1888/9 to 1913) that had no clear record of small enterprise development policy. Minilk's attempts also failed to bring either value or sectorial transformation since there was absence of institutional and public policy support (Belay, 2000; Mulugeta, 2011).

As a result of the radical change in the government's standpoint towards socioeconomic alteration during Emperor Haile Selassie's regime (1935 to 1974), the MSEs have shown some progress. According to CSA (1991) $\&$ Desta (2010), even if there was a shortcoming, the numbers of enterprises were about 400 during this period, including both small and medium and a few large-scale enterprises.

After the introduction of socialism, which is during the regime of Dergue (1974 to 1991), the government established the Handicraft and Small-scale Industries Development Agency to regulate the activities of small enterprises and to conduct promotional activities in 1977. Later on, by proclamation 1978 "Handicrafts Producers Cooperatives" was established to coordinate their activities (Wole, 2004). In this way, the Dergue rule established a new policy guideline, with a particular emphasis on small enterprise industries, which were revolutionary in the Ethiopian context by then (Mulatu, 2005). However, the cooperation practices of the Dergue regime were not autonomous organizations, but had purely political character ultimately the efforts ended in a complete policy failure (McCarthy, 2001).

Being cognizant of the role of the micro and small enterprises as important vehicles in addressing the challenges of unemployment, economic growth and equity in stimulating capital formation, employment creation and economic development since 1991, the Government of the Federal Democratic Republic of Ethiopia has given a due attention to the development of micro and small enterprises (Kamunge et al., 2014 cited in Mesfin, 2015). In Ethiopia, MSEs are the second largest employment-generating sector next to agriculture (Haftom et al., 2014). This sector is also recognized as the basis for medium and large-scale enterprises (Gebeyehu \& Assefa, 2004). In November 1997, MoTI published the MSEs development strategy, which initiated systematic approaches to alleviate problems and promote the growth of small enterprises (MoTI, 1997).

According to this policy document, elements of the programme include measures to create an enabling legal framework and to streamline regulatory conditions that promote the expansion and evolution of existing and new small enterprises. The specific support programmes include measures related to facilitating access to finance and training, appropriate technology, access to counseling and infrastructure and institutional strengthening of the private sector and chamber of commerce (Eshetu \& Eleke, 2008).

The Government of the Federal Democratic Republic of Ethiopia has earmarked the sector as an instrument to bring about economic transition by effectively using the skills and talents of the people. Particular interest has been paid to the process of expansion of small enterprises into medium and larger sized enterprises to a point at which their contribution to the socio-economic growth of the country has increased (Fredu \& Edris, 2016).

In Ethiopia, despite the enormous importance of the MSEs sector to the national economy with regards to job creation and the alleviation of abject poverty, many of the MSEs are unable to realize their full potential due to the existence of different factors that inhibit their growth and performance (ibid).

\subsection{The Role of MSEs in Socio-Economic Development}

With regard to the contribution of MSEs in developmental aspects, there were controversial issues among scholars. That means there have been a number of debates on the arguments for and against the roles the sector plays in the development perspectives.

In line to this, findings of numerous researchers confirm that in countries where the policies of their governance favors MSEs, adequate supports were provided and members are committed to achieve the goals they are established for, MSEs have found to be effective and vibrant (Desalegn, 2019). As to Fredu \& Edris (2016), MSEs have usually been perceived as the dynamic force for sustained economic growth and job creation. They play assorted roles as boosting competition, innovation, as well as improvement of human capital and creation of a financial system around the globe.

With particular emphasis to Ethiopia, the sectors have multifaceted role in socio-economic development. They are taken as an instrument in bringing about economic transition by effectively using the skills and talents of the people particularly women and youth without demanding high-level training, much capital and sophisticated technology. In line to this, the report of the Federal Urban Job Creation and Food Security Agency (FUJCFSA) cited in the National Bank of Ethiopia (NBE) (2018) confirmed that MSEs have lifted millions of Ethiopians out of abject poverty. According to CSA in Gebrehiwot \& Wolday (2006), there were 799,358 establishments employing 997,380 individuals. Evidence from the annual report of the NBE (2018) signified that the industrial 
sector showed 12.2 percent output growth and registered 27 percent share in Gross Domestic Product (GDP). The sector contributed $40.7 \%$ to the overall economic growth during the fiscal year.

On the contrary, other researchers claim that the role of MSEs is insignificant in the socio-economic development. The mortality and liquidation rates of MSEs are very high irrespective of various policy initiatives introduced by African governments including Ethiopia to accelerate the growth and survival of these sectors. Therefore, their performance has remained unsatisfactory in many countries (Gebeyehu \&Assefa, 2004).

As study made by Belay (2000) reveals $98 \%$ of business firms in Ethiopia were MSEs, of these, $33 \%$ of them were small enterprises, with only $2 \%$ represented by middle and large scale industries. Moreover, data from CSA (2003) designates that three out of five small businesses fail within the first few months of their operations and there are no robust medium-sized enterprises. With this regard Assefa (1997); Andreff \& Dominique (2001) proved that most MSEs are either in liquidation or only bordering on survival. This indicates that majorities of the MSEs fail to grow into the next stage where they can be more efficient and develop a global chain of production.

These findings reflect that although the roles of small enterprises in the overall national welfare are assumed to be substantial, their contribution to the industrial sector in particular and to the national GDP in general is not significant. In other words, the growth of small enterprises is still in its infancy and requires special attention from government and other concerned bodies.

In conclusion, from the view point of the reviewer, had the countries provided enabling policies and regulations of MSEs, members (entrepreneurs) play their role properly and all stakeholders add their roles to resolve factors inhabiting the performance of MSEs, the significant contributions of the sectors in the socioeconomic advancement of the countries are undeniable. They are catalysts in the socio-economic development of any country. They lay foundation for industrialized economy. In the Ethiopian context, they are the key vehicles to achieve the objectives of Transformation Plan II, which is to serve as a spring board towards realizing the national vision of becoming a low middle-income country by 2025 . This enables to attain inclusive economic growth, which accelerates economic transformation and the journey towards the country's renascence.

\section{Major Challenges Hindering the Performance of MSEs in Ethiopia}

In spite of the numerous attempts made by governments and donor organizations to encourage MSEs, the growth and performance of the sector has been influenced by several aspects. So far, numbers of studies have been conducted to identify factors attributed for poor performance of MSEs. These can be categorized as internal and external factors. Internal factors include entrepreneurial (personal traits) and management factors (Abera, 2012). A study conducted by Worku (2009) investigated that high level of managerial skills significantly promotes longterm survival and profitability in MSEs. According to his finding, managers of bankrupt enterprises do not have the experience, knowledge, or vision to run their businesses. Through his assessment, he found that the root cause of small firm collapse was management incompetence. On the other hand, external factors are factors outside of the enterprises that include marketing factors, working place factors, technology, financial factors, infrastructure, and factors related to the enabling business environment.

In overall, despite the numerous determinants of growth and expansion in micro and small enterprises, in this reviewed article, the major challenges identified are: finance, managerial, technology and technical skills, business development services, marketing, infrastructure, policy and institutional linkage-related problems as major obstacles in the performance of the small enterprise sector.

\subsection{Financial Challenges}

As the circulation of blood is necessary for maintaining life in human body, in the same way finance is the life blood of any business (Ramachandran \& Srinivasan cited in Desalegn, 2019). In the growth and development of small enterprises, lack of access to finance is the major obstacles as quite lots of economists have verified (MoTI, 1997). The availability of finance is vital for dynamic enterprises. However, since there are limitations in the credit markets of developing countries, the majority of entrepreneurs start their businesses with little or no support from formal financial institutions (Barney, 1991).

According to ISA (2000), large proportions of small enterprises in Africa operate with financial limits due to lack of credit arising from the weaknesses in the financial markets. For instance, as to Tyra Reliey cited in NTSIKA (2004), promotion enterprises has reported that from the formal sectors, only $2 \%$ of small enterprises in the world have access to financial services. The survey result of the CSA (2003) show that in Ethiopia for about 50 percent of the sector's operators, the main difficulty when starting their operation is a lack of sufficient initial capital. This issue becomes more critical when they decide to expand their businesses (Arimah, 2001). Banks are unwilling to offer loans on the assumption that the risk accompanying loans to small enterprises is high resulting in challenge to small-scale enterprises (USAID, 2002). Countless micro and small enterprises also rarely approach formal financial institutions, as they are not confident of obtaining loans (Huang \& Brown, 1999). Their limited experience with bank officials has done little to change their perceptions of the difficulties and bureaucracy intertwined in obtaining credit. 
In addition, the low returns expected from small loans provided to small enterprises have jeopardized their relationship with formal financial institutions. The inability of entrepreneurs in small enterprises to provide precise information about themselves has also contributed to the lack of access to credit (Kavanamur, 2002).

Collateral is seen as a way of reducing risk, simplifying the process of selection and as an instrument for recompensing for bad debts, according to the formal money-lending institutions (Mishkin, 2006). In this regard, economists have observed that the most widely accepted forms of collateral in most credit markets are mobile and fixed assets such as motor vehicles, real estate and industrial equipment; that are rarely achieved by entrepreneurs in micro and small enterprises of developing countries in particular (Monk, 2000).

Regardless of the fact that there are many financial institutions to extend credit facilities, small firms are still generally short of credit (Abdullah \& Baker, 2000). Thus, as an option, small firms start their businesses with their own savings, supplemented by borrowing from friends and relatives. They meet their capital requirements by approaching informal credit institutions that exist within their community (Charmes, 2000). In the works of Carpenter \& Petersen (2002), it is indicated informal financial institutions such as "Iqqub" serve as an alternative to fill the gap for the majority of small enterprises. These are traditional financial institutions that are based on mutual trust among the members and that vary in size, capacity and function. They run on a cyclical basis, satisfying the demands of only one member at a time. Other members must wait their turn and the last member receives a lump sum only at the very end of the cycle. Iqqub schemes promote the viability of a small enterprise through enhancing own savings, conversion of savings into investments and reduction of transaction costs in credit markets (Adera, 1995). In general, financial factors play decisive place in the success of micro and small enterprises.

\subsection{Managerial, Technological and Technical Skills Related Challenges}

Lack of managerial skills leads to problems in production due to lack of coordination of production process in business (College Level Examination Placement) (CLEP, 2006). Incapable manager cannot properly implement all the three business process types like core business, organization management and supporting processes. Due to this, they cannot run all the activities of the enterprises either by themselves or they cannot afford to employ specialists in the fields of planning, finance and administration. In this regard, the study made by Aremu \& Adeyemi (2011) deduced that decision-making skills, sound management and accounting practices are very low for MSEs operators in developing countries.

Lack of the necessary technology is also the other area which impedes the development of MSEs. According to Beck \& Levine (2003), technology designates a combination of machinery, labor, skills and techniques. These technologies need to be consistent with local resources and conditions in order to make effective use of the relatively abundant resources. Nonetheless, the issues of adopting appropriate technology and the limited access to this type of technology have presented serious problems and obstacles for operators of small-scale enterprises (YU, 2002). Among the entrepreneurs studied by the CSA in Ethiopia, 29\% stated machinery failure as the major causes for the entrepreneurs' inability to be operational (CSA, 2003). In general, limited knowledge and ability of the (manager) owner or shortage of competent staff to advice the owner on management policies are one of the severe challenges hindering the performance of MSEs. These all signify education and trainings are needed for MSEs to appropriately run their activities.

\subsection{Business Development Services}

These are defined as a wide range of non-financial services such as training, counseling, technology development and its diffusion (Leidholm, 2002). Business development services enable small enterprises to become productive and to effectively reduce poverty by contributing to the development of local economies.

In most developing countries, the majority of enterprises have no access to business development services (Ishengoma \& Kappel, 2006). This is mostly because institutions that can provide such services do not exist or because entrepreneurs are unaware that the service is offered in their country, while others are ignorant of the significance of the service (Fay \& Clark, 2000). In fact, the presence of a strong institution that can provide reliable and timely information through efficient information systems is crucial for their success. For the growth and expansion of small enterprises, information related to market, raw materials, technology, business opportunities, government policies and regulations are preconditions (Rosmary, 2001). To sum up, to solve the challenges related to managerial, technology and technical skill and business development services, education and trainings are highly needed for MSEs to appropriately run their activities.

\subsection{Marketing Challenges}

To realize competitive advantage, access to markets is crucial. In the opinion of Beck \& Levine (2003), not having access to markets negatively affects the entrepreneurs' performance. For example, in terms of location, the majority of small enterprises are home-based with limited markets for their products and services (Paul \& Rahel, 2010). Their interaction with other businesses increases transaction costs and this contributes to limited access to 
marketing information (Gebeyehu \& Assefa, 2004). Supply shortages are also considered as obstacle to the normal functioning of enterprises in one way or another. These limit the ability of entrepreneurs in micro and small enterprises to generate goods and services for better income generation (Ishengoma \& Kappel, 2008).

On the other way, demand constraints also hinder the opportunities for production on small enterprises (Gebrehiowot \& Welday, 2004). In this regard, Ken (2003) addressed that small enterprises are facing "too much competition", citing the existence of congestion in the market and failure of demand to grow, at least not as rapidly as the supply. Nevertheless, if proper policies applied, ultimately better demand would be created for smaller enterprises' outputs, which would open up new opportunities for their growth.

In connection to this, market constraints practiced by small enterprises have been listed as among the most severe obstacles to growth beyond subsistence level (Negash \& Kena, 2003). The survey result, which is based on 31,863 small-scale industries all over the country, indicated that $48 \%$ of all enterprises encountered problems related to demand or access to markets, and weaknesses in or total deficit of suitable marketing channels, exhibitions, trade fairs and display centers (CSA, 2003).

Apart from this, shortages of inputs and their costs are common constraints. In line to this, even if specific problems vary by country, the most basic element in all this is whether entrepreneurs concern access or their costs as the premier pressing problem (Solymossy \& Penna, 2000).

\subsection{Absence of Adequate Infrastructure}

It is obvious fact that the Ethiopian economy in general is affected by inadequate infrastructures which highly retard the growth of small units including MSEs in particular. Most of the small units and industrial estates found in towns and cities are having one or more problems of basic utilities like power supply, water and drainage, roads, working areas and telecom supplies. Lack of sufficient raw materials and marketing problems are also part of necessary services as mentioned earlier.

Due to the illustrated problems, some of the MSEs look for alternatives to get the necessary facilities by themselves through various mechanisms, which highly influence their profitability. Thus, absence of work premises, high rent and poor access to good quality business infrastructure are identified as the other hindering force for entrepreneurs running small enterprises (Liedholm, 2002). In addition, in the survey report of CSA ( 2003), problems related with the working premises are mentioned as one of the main constraints hampering the normal performance of small enterprises. Practical experience in Ethiopia shows that some enterprises operate in open and crowded spaces, a situation that limits their access to basic utilities such as toilets, water and electricity supplies. This situation is prominent in urban centers and in small villages which have chance of township in the future. The main reason for enterprises being concentrated in urban areas is the relative existence of several types of infrastructure preferable to rural areas (Liedholm \& Mead,1999). However, the scarcity of such infrastructure has also been one of the main impediments to the growth of the sector in many urban areas of the country (Mulatu, 2005). In short, the absences of adequate infrastructure adversely affect the quality, quantity and production schedule of the enterprises which ultimately results in under-utilization of capacity.

\subsection{Policy Related Challenges}

For small enterprises to be competent enough both locally and internationally, they require favorable policies that speeds up their growth, a good incentive package and inspiring business environments to produce products they are in need (Arimah, 2001). A government that is committed to the promotion and development of small enterprises makes fiscal policy and monetary setting stable with reasonable interest and exchange rates (Berry, 1995). Furthermore, financial markets and tax rates should be stable and moderate together with endorsing policies that minimize the cost of business registration and licensing.

In many countries, the overall economic policies such as trade, pricing, taxation and credit policy are biased in favor of large enterprises (Huang \& Brown, 1999). Under trade policy, for example, government can directly allocate import inputs and this favors large enterprises that are more likely than smaller ones to gain access to import quotas. Large enterprises are often granted industrial investment incentives that allow them to import their capital goods duty-free for a certain period (Ishengoma \& Kappel, 2006).

In the case of policy biases that favor large firms over small enterprises, attempts have been made to quantify policy-induced cost differentials between small and large enterprises in accessing resources such as labor and capital (Gebrehiwot \& Welday, 2004). However, such bias is often difficult to explain as some policies may be biased against small enterprises while others favor them.

Besides, as to Paul \& Rahel (2010), measuring policy-induced price differentials is difficult as not all such differentials are policy-induced; they may be the result of quality differences in the case of labor or finished products or differences in risks or administrative costs in the case of capital price differences may also arise from private sector habits or strategies rather than from policies.

There are also complex and burdensome government rules and regulations that emanate from a perception that small enterprises neglect business regulations and therefore operate under illegal conditions, disobeying one 
or more government rule (Liedholm, 2002). Such infractions could result in penalties in the form of a lump-sum fee, which would result in a reduction of income for business operators (Mensah, 2005). In extreme cases, it could result in the closure of a business or the confiscation of a business's property, creating uncertainty and discouraging business investment.

\subsection{Institutional Linkage Challenges}

Linkage with other enterprises and related sectors is of the most important issues affecting the growth of small enterprises. In most cases, the nature of these linkages and commercial relationships between small and bulky enterprises is weak and unbalanced, which harms the smaller enterprises (Rosmary, 2001). The most dominant linkage relationship between these two types of enterprise is one in which medium and large enterprises provide inputs to small enterprises; this is regarded as exploitative (Chen, 2005).

In developing countries like Ethiopia, an effective linkage, in which small enterprises supply medium and large ones and which is believed to have a positive effect on the performance of the small enterprise is not very common (Ishengoma \& Kappel, 2006). This imbalance in linkages between sectors is among the factors that explain low competency in the small enterprise sector. As a result of their fragile legal status and poor capabilities, the majority of small enterprises that are involved in bilateral vertical linkages with medium and large enterprises have relatively low bargaining power (Gebrehiwot \& Welday, 2004). Subsequently, they are likely to be oppressed and to incur relatively high transaction costs.

\section{Methodology}

For the purpose of writing this article, best evidence review type is used. The data has been collected from various secondary sources. Thus, the article review is based on secondary data obtained from different scholars and authors. To achieve the aim of this article review, relevant literatures were collected from Google Scholar using academic search engines by entering relevant key words in the internet based search engines. In addition, policy and regulatory framework documents, past study reports and periodic activity reports, the revised Micro and SmallScale Enterprises Growth Stages Guideline No.004/2011 were reviewed. The most prominent secondary data were obtained from the Federal Urban Job Creation and Food Security Agency of the country. These data were examined and interpretations were done to show the tendencies and status MSEs in Ethiopia. Basing the objectives of the sector, the practical situation in the sector is examined and the problems encountering were identified. Eventually, the proposed interventions and strategies to be adopted are indicated.

\section{Conclusion and Proposed Interventions \\ 5.1 Conclusion}

MSEs are usually considered as the engine of economic growth, which facilitate equitable development in both developed and developing countries. In countries like Ethiopia where there is large population and the economy is dominated by agricultural sector, MSEs are highly significant. In this article review, researchers view point is categorized into for and against MSEs contribution to GDP based upon the practical conditions existing in countries.

Any ways, majority of scholars agree that in countries where supporting policies and regulations of MSEs are provided, members (entrepreneurs) perform their duties appropriately and all stakeholders contribute their roles to resolve factors inhabiting the performance of MSEs, the significant contributions of the sectors in the socioeconomic advancement of the countries are undeniable. They lay foundation for industrialized economy. In the Ethiopian context, they are the key vehicles to achieve the objectives of Transformation Plan II. Eventually, challenges to the development of MSEs are identified and elaborated, which requires the intervention of all stakeholders.

\subsection{Proposed Interventions}

From discussions made so far, MSEs play crucial roles which any sectors cannot compensate in countries like Ethiopia. This means to enable to realize rapid growing goals through MSEs is the most recommended option in developing countries having complex economic progression backlogs like Ethiopia. Regardless of the multifaceted contributions the MSEs bring in overall developmental aspects of countries, factors mentioned above are hindering in accomplishing their aforementioned roles. Hence, finding solutions to all these challenges could not be the duty of an individual or single organization even if the largest share is expected from the government. This is to say the obstacles can be tackled by collective efforts of all stakeholders among which structures of the government at all levels including their agencies, banks, regulatory authorities, tax authorities, TVET, the employees of MSEs, multilateral and bilateral agencies and donors. Moreover, the efforts of the entrepreneurs (members of MSEs) have to be added to what others would exploit. Therefore, the commitment and loyalty of the entrepreneurs have non replaceable position in the success of the enterprises. 


\section{Acknowledgments}

First and foremost, I would like to thank the Almighty God for this wonderful opportunity he has given me to write this article review. Hence, I owe special thanks to the Almighty God for His forgiveness, kindness and blessings that gave me life to this date and made my entire journey successful. In fact, I would like to give all the praise to my savior, Jesus Christ for his immense care and the success he has done in my entire life. It is by his mercy that I am writing this review today and thus, be glory and respect for Him now and forever. Finally, I thank all authors of those materials I used to refer.

\section{References}

Abdullah, M., A. \& Baker, M. (2000). Small and Medium Enterprises in Asian Pacific Countries: American Journal of Small Business, vol.5.

Abera, A. (2012). Factors Affecting the Performance of Micro and Small Enterprises in Arada and Lideta Sub Cities in Addis Ababa: MSc Thesis, Addis Ababa University, Addis Ababa.

Adera, A. (1995). Instituting Effective Linkages between Formal and Informal Financial Sector in Africa, Savings and Development, 26(4).

Ageba, G. \& Amha, W. (2003). Policy Impact and Regulatory Challenges of Micro and Small Enterprises in Ethiopia, Working Paper: Ethiopia Development Research Institute, Addis Ababa.

Anamakwe, C. (2001). The Challenges and Prospects of Small Scale Industries in Nigeria: Problems and Prospects Workshop on Grassroots Advocacy and Economic Development, 11-13.

Andreff, M. \& Dominique, R. (2001). Start-Ups and Job Creations: Econometric Study on Panel Data, Myths and Realities of Business Creation, Discussion Paper. France: University of Marnela-Vallee.

Aremu, M., A. \& Adeyemi, S. L. (2011). Small and Medium Scale Enterprises as a Survival Strategy for Employment Generation: Journal of Sustainable Development, 4 (1), 200-206.

Arimah, B., C. (2001). Nature and Determinants of Linkages between Formal and Informal Sector in Nigeria. Nigeria: African Development Review.

Assefa, A. (1997). Comparative Analysis of the Development of Small Industry in Region 14 with other Regions. Proceedings of the $6^{\text {th }}$ Annual Conference on the Ethiopian Economy.

Audretsch, D. (2005). The Economic Role of Small and Medium Enterprises: Journal of Business Economics, 22(5).

Barney, J., B. (1991). Firm Resources and Sustained Competitive Advantage: Journal of Management, 13(2).

Beck, T. \& Levine, R. (2003). Small and Medium Enterprises, Growth and Poverty: Cross Country Evidence: World Bank, New York.

Belay, G. (2000). Evaluation of the Performance of the Private Sector Economy in Ethiopia (1991 to 1999): Ethiopian Ministry of Trade and Industry, Addis Ababa.

Berry, A. (1995). Creating and Enabling Policy Environment for Small Enterprises: Traditional and Innovative Approaches: Centre for International Studies, Toronto.

Carpenter, R. \& Petersen, B. 2002. Is the Growth of Small firms constrained by internal finance? Journal of Economics and Statistics, 84(2).

Chen, M. (2005). Business Environment and Informal Economy: Creating Conditions for Poverty Reduction: Chamber of Commerce, Addis Ababa.

CSA (1991). Population and Housing Census of Ethiopia: Analytical Report at National Level. Ethiopia: Central Statistical Authority.

CSA (2003). Urban Informal Sector Sample Survey: Central Statistical Authority of Ethiopia, Addis Ababa.

Charmes, J. (2000). Contributions of Informal Sector to GDP in Developing Countries: Assessment, Estimates, Methods, Orientation for the Future, of the $4^{\text {th }}$ Proceedings.

CLEP (2006). Entrepreneurship: Unpublished manuscript, Addis Ababa, Ethiopia.

Craig, B., R, Jackson, W., E. \& Thomson, J., B. (2007). Small Firm Finance, Credit Rationing, and the Impact of SBA-Guaranteed Lending on Local Economic Growth. Journal of Small Business Management, 25(6).

Desalegn Fekadu (2019). Assessment of the Role of Research in Moulding Cooperative Policies in Ethiopia: Public Policy and Administration Research, Vol.9, No.5,

Desta, S. (2010). Studies Conducted on Women Entrepreneurs in Ethiopia: Private Sector Development. Addis Ababa: Chamber of Commerce and Sectorial.

Eshetu, B. \& Eleke, W. (2008). Factors that Affect the Long-Term Survival of Micro, Small and Medium Enterprises in Ethiopia: South African Journal of Economics, 6(3).

Fay \& Clark (2000). Small and Medium-Sized Business Imperatives. Boston: Homewood.

Fredu Nega \& Edris Hussein (2016). Small and Medium Enterprise Access to Finance in Ethiopia: Synthesis of Demand and Supply: the Horn Economic and Social Policy Institute, Working Paper 01/16, Ethiopia.

FeMSEDA (2011). Improved Micro and Small Enterprises Strategy of 2011. A. A. Ethiopia.

Fredu Nega \& Edris Hussein (2016). Small and Medium Enterprise Access to Finance in Ethiopia: Synthesis of 
Demand and Supply: The Horn Economic and Social Policy Institute (HESPI), Working Paper 01/16

Gebeyehu, W. \& Assefa, D. (2004). Role of Micro and Small Enterprises in the Economic Development of Ethiopia: Federal Micro and Small Enterprises Agency, Addis Ababa.

Gebrehiowot, A. \& Wolday, A. (2004). Policy Impact on Regulatory Challenges of the Micro and Small Enterprises in Ethiopia. Proceedings of the 2nd International Conference on the Ethiopian Economy: Ethiopian Economic Association. Addis Ababa.

Gebrehiwot Ageba \& Wolday Amha (2006). Micro and Small Enterprises (MSE) Development in Ethiopia: Strategy, Regulatory Changes and Remaining Constraints: Ethiopian Journal of Economics, Vol. X, No. 2.

Goedhuys, M. (2002). Employment Creation and Employment Quality in African Manufacturing Firms. Geneva: International Labour Office.

Gurmeet, S. \& Rakesh, B. (2008). Entrepreneurship and Micro and Small Enterprises in Ethiopia: Evaluating the Role, Prospects and Problems Faced by Women in this Emergent Sector: International Journal, 23(2).

Hailai Abera Weldeslassie, Kibrom G/kristos, Lubak Minwyelet, Mahlet Tsegay, Negasi Hagos Tekola \& Yemane Gidey (2019). Analyzing and Profiling Micro, Small and Medium Enterprises (MSMEs) in Generating Income, Job, Igniting Entrepreneurship and Contributions to GDP: Evidence from Northern Ethiopia: Research Gate, DOI: 10.2139/ssrn.333970.

Haftom Haile Abay, Fisseha Girmay Tessema \&Araya Hagos Gebreegziabher (2014). External Factors Affecting the Growth of Micro and Small Enterprises in Ethiopia: A Case Study in Shire Indasselassie Town, Tigray: European Journal of Business \& Management, Vol.6, No.34.

Harabi, N. (2003). Determinants of Firm Growth: an Empirical Analysis from Morocco. Northwestern Switzerland: Solothum University of Applied Sciences.

Harding, A. (2002). Survival and Success in African Manufacturing Firms: Centre for Study of African Economies, $82(7)$.

Huang, X. \& Brown, A. (1999). Analysis and Classification of Problems in Small Business: International Small Business Journal, 18(1).

ISA (2000). Credit Constraints in Manufacturing Enterprises in Africa: Industrial Survey Group. (Working Paper 24), UK.

Ishengoma, K. \& Kappel, R. (2006). Economic Growth and Poverty: Does Formalization of Informal Enterprises Matter? Hamburg: German Institute of Global and Area Studies.

Kavanamur, D. (2002). Credit Information Sources for Small Enterprises, New Guinea: University of Papua.

Ken, K. (2003). Maximizing the Benefits of Globalization for Africa. Proceedings of International Conference on Trade and Investment, Dakar, 23-26 April.

Liedholm, C. (2002). Small Firm Dynamics: Evidence from Africa and Latin America: Small Business Economics, $18(5)$.

Liedholm, C. \& Mead, D. C. (1999). Small Enterprises and Economic Development: the Dynamics of Micro and Small Enterprises: Rout Ledge Studies in Development Economics, New York.

Lutkenhorst, W. (2004). Economic Development, the Role of Micro and Small Enterprises and the Rationale for Donor Support: Some Reflections on Recent Trends and Best Practices: Proceedings of the Micro and Small Enterprises Partnership Group Meeting, 19(5), Hanoi.

McCarthy (2001). "The History of Agricultural Cooperatives" in Cooperative Business Today. First Quarter, Vol.1, Issue 1, VOCA- Addis Ababa, Ethiopia.

Mishkin, F. (2006). Economics of Money, Banking and Financial Markets. $6^{\text {th }}$ ed, Massachusetts: Addison-Wesley.

Mensah, J., V. (2005). Small-Scale Industry as a Sponge, Empirical Survey in the Central Region: Singapore Journal of Tropical Geography, 26(2), Ghana.

Mesfin Seyoum Kebede (2015). Challenges and Prospects of Small Enterprises in Ethiopia: A Study of Entrepreneurs in Tigray Region, $\mathrm{PhD}$ Thesis at University of South Africa.

Mohammed Getahun (2016). The Challenge and Prospects of Small Scale Enterprise in Ethiopia: A Survey of Some Selected Small Scale Enterprise in Addis Ababa City: International Journal of Scientific and Research Publications, Volume 6, Issue 5.

Monk, R. (2000). Why Small Businesses Fail? CMA Management, 74(6).

MoTI (1997). Micro and Small Enterprise Development Strategy of Ethiopia, Addis Ababa.

Mulatu, D. (2005). Small Businesses in Small Towns of the Eastern Tigray Region: Nature and Economic Performance: Chamber of Commerce, 208, Addis Ababa.

Mulugeta, C. (2011). Factors Affecting the Performance of Women Entrepreneurs in Micro and Small Enterprises (the case of Dessie Town), MA Dissertation, Bahir Dar University.

Mulu, G. (2009). Innovation and Micro Enterprises' Growth in Ethiopia: Institute for Development and Economic Research, 24(51).

Muma, P., A. (2002). Small Business in the South Pacific: Problems, Constraints and Solutions. Suva: Zania Books. National Bank of Ethiopia (NBE) (2018). Annual Report 2014-15. Addis Ababa, Ethiopia. 
Negash, Z \& Kena, T. (2003). State, Growth and Dynamism of Micro and Small Enterprises in Mekele. Mekele University of Ethiopia: Microfinance Program and Economic Development.

NTSIKA (2004). Annual Review: Enterprise Promotion Agency, Small Business Monitor, 2(1).

Paul, I. \& Rahel, W. (2010). Growth Determinants of Women-Operated Micro and Small Enterprises in Tigray Region: Journal of Sustainable Development in Africa, 25(6).

Rahel, W. \& Issac, P. (2010). Growth Determinants of Women-Operated Micro and Small Enterprises in Addis Ababa: Journal of Sustainable Development in Africa, 12(6), Clarion University of Pennsylvania, Clarion, Pennsylvania.

Ramachandran, R. \& Srinivasan, R. (2010). Financial Management, Sriram Publications, 1-G kalyanapurm, Tennur, Trichy-17.

Rosmary, A. (2001). Formal and Informal Institutions' Lending Policies and Access to Credit by Small-Scale Enterprises in Kenya: An Empirical Assessment: The African Economic Research Consortium, 21(5).

Schramm, C., J. (2004). Building Entrepreneurial Economies, Foreign Affairs, 83(4) Sharma, B.A.V. 1983: Research Methods in Social Sciences. New Delhi: Sterling Publishers Pvt. Ltd.

Solymossy, E. \& Penna, A., A. (2000). Sustainable Growth for the Small Business: a Theory of Organizational Transition, Illinois: Western Illinois University.

Tariku Ayele (2018a). Factors Affecting the Performance of Micro and Small Enterprise in Ethiopia: International Journal of Political Science and Development, Vol. 6(8), pp. 275-279.

(2018b). Status of Micro and Small Enterprise (MSE) Development in Ethiopia: European Journal of Business and Management, Vol.10, No.31.

Taye, M. (1998). Age-Size Effects in Firm Growth and Productive Efficiency: The Case of Manufacturing Establishments in Ethiopia. retrieved from: http://www.ideasrepec.org.

Timmons, J. \& Spinelli, S. (2004). New Venture Creation. Entrepreneurship for the $21^{\text {st }}$ century. $6^{\text {th }}$ ed. Boston : McGraw Hill Companies.

USAID (2002). What Makes Small Firms Grow? A study of Success Factors for Small and Micro Enterprise Development, Romania: Bucharest.

Wolday Amha (2015). Growth of Youth-owned MSEs in Ethiopia: Characteristics, Determinants and Challenges: Ethiopian Journal of Economics, Vol. XXIV, No. 2.

Wole, S. (2004). The Micro and Small Enterprises Sector in Ethiopia: An Overview in the Role of Micro and Small Enterprises in the Economic Development of Ethiopia, W. Gebeyehu and D. Assefa, Eds: FeMSEDA, Addis Ababa.

Worku, Z. (2009). "Efficiency in Management as a Determinant of Long-term Survival in Micro, Small and Medium Enterprises in Ethiopia." Problems and Perspectives in Management, 7(3):1-9.

Yared Teshome Geneti (2017). Challenges and Opportunities of Micro and Small Enterprises Strategy in Ethiopia Urban Development: the Case of Ambo Town, Oromia Ethiopia: Institutes of Development Studies, University of Mysore, Karnataka, India, pp 55-64.

Yu, S., O. (2002). Infrastructure Development and the Informal Sector: ILO Employment-Intensive Investment Branch, Geneva.

Zewde, K. (2002). Jobs, Sex and Small Enterprises in Africa: Women Entrepreneurs in Ethiopia: A Preliminary Report, ILO, Geneva, Ifp/Seed-Wedge. 